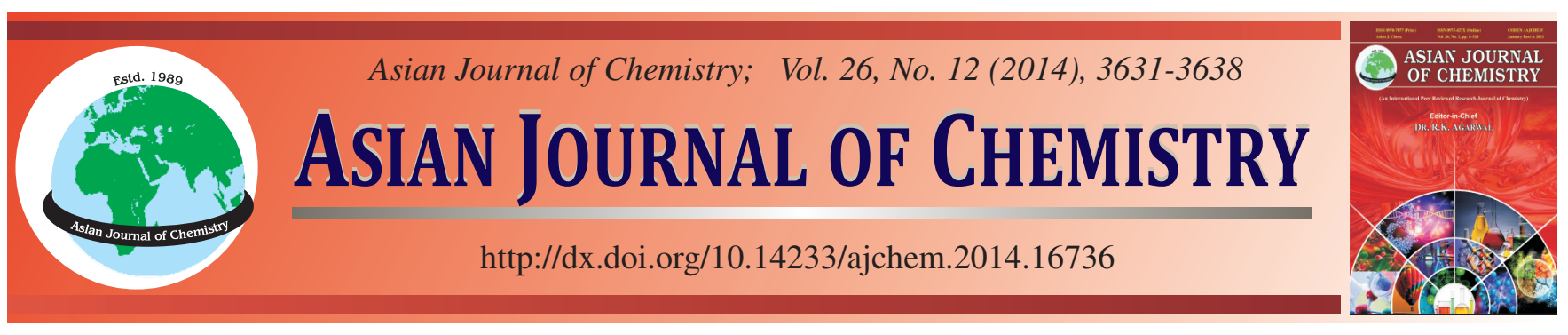

\title{
Toxicological Effects of Crude Oil: Integrated Biomarker Responses in the Hepatopancreas of Clam Ruditapes philippinarum
}

\author{
Bin Xia*, Bijuan Chen, Xuemei Sun, Yi Cui, Jun Zhao and Keming Qu
}

Key Laboratory of Sustainable Utilization of Marine Fisheries Resources, Ministry of Agriculture, Yellow Sea Fisheries Research Institute, Chinese Academy of Fisheries Sciences, Qingdao 266071, P.R. China

*Corresponding author: Fax: +86 532 85812371; Tel: +86 13853274817; E-mail: xiabin@ysfri.ac.cn

Keywords: Petroleum, Integrated biomarker responses, Clam, Crude oil, Ruditapes philippinarum.

\section{INTRODUCTION}

Marine oil pollution is a global environmental issue. Petroleum hydrocarbons can enter the marine environment via numerous sources, including oil spills, effluent discharge from petrochemical industries and urban runoff ${ }^{1,2}$. Spills from tanker accidents are also a major source of marine oil pollution ${ }^{3}$. Pollution events provoked by oil spills have occurred all over the world, some of them on large scales, such as the Exxon Valdez (1989, Alaska), the Prestige (2002, Spain) and the Deepwater Horizon (2010, Gulf of Mexico). Several similar incidents have also occurred in China, caused mainly by sea floor oil leaks, such as the Penglai 19-3 oil spill (2011). In addition, petroleum tanker spills, i.e. the Tasman Sea (2002) and the arteaga (2005) and ruptured petroleum transportation ducts, like the Dalian Xingang oil pipeline explosion (2010), have also contributed to marine contamination. Crude oil is a complex mixture that consists of volatile lighter monoaromatic compounds, i.e. benzene and toluene and the more persistent aromatic compounds, i.e. polycyclic aromatic hydrocarbons (PAHs), which include benzo(a)pyrene and anthracene, etc. After an oil spill, a series of physical, chemical and biological processes take place. These include spreading, evaporation, dissolution, dispersion, absorption, sedimentation, biological decomposition and photo-oxidation. The oil substances are partially physically transferred and biologically decomposed and the rest dissolves in the seawater forming the water-soluble fraction (WSF). The water-soluble fraction is mainly composed of single ring aromatic hydrocarbons (toluene, benzene, xylene and di- and trimethyl benzenes), cycloalkanes (sterane and terpane) and very low concentrations of $\mathrm{C}_{12}-\mathrm{C}_{24} n$-alkanes. The low boiling aromatics are the primary toxic agents for aquatic $\operatorname{organisms}^{4-7}$.

At a biochemical level, exposure to organic pollutants may induce a number of reactive oxygen species (ROS) in living organisms, causing oxidative damage. Reactive oxygen species include superoxide anion radical $\left({ }^{*} \mathrm{O}_{2}{ }^{-}\right)$, hydrogen peroxide $\left(\mathrm{H}_{2} \mathrm{O}_{2}\right)$ and the highly reactive hydroxyl radical $(* \mathrm{OH})$. Living organisms can develop antioxidant defenses to minimize oxidative damage to their cellular components, proteins and DNA. Antioxidant enzymes play an important role in eliminating ROS. Therefore, organisms can acclimatize to increasing ROS production via antioxidant enzyme up-regulation ${ }^{8}$. The antioxidant enzymes can either be induced by adaptive responses, or inhibited by toxic reactions. Failure of antioxidant defenses to detoxify excessive ROS production can result in the inactivation of enzymes, peroxidation of membrane lipids and DNA strand breaks ${ }^{9-11}$. The most important antioxidant enzymes include superoxide dismutase (SOD, EC 1.15.1.1), catalase (catalase, EC1.11.1.6), glutathione peroxidase 
(glutathione peroxidase, EC 1.11.1.9) and peroxidase (POD, EC 1.11.1.7). superoxide dismutase converts $* \mathrm{O}_{2}{ }^{-}$to $\mathrm{H}_{2} \mathrm{O}_{2}$, catalase reduces $\mathrm{H}_{2} \mathrm{O}_{2}$ to water and oxygen, glutathione peroxidase catalyzes $\mathrm{H}_{2} \mathrm{O}_{2}$ transformation into water using glutathione (GSH) and peroxidase reduces $\mathrm{H}_{2} \mathrm{O}_{2}$ to water using various substrates as electron donors. Glutathione S-transferases (GST, EC 2.5.1.18) catalyze the conjugation of electrophilic compounds with GSH and they play a role in preventing oxidative damage by conjugating the breakdown products of lipid peroxides to GSH.

Biomarkers are measurements of body fluids, cells, or tissues at cellular, biochemical and molecular levels that indicate the presence of pollutants (exposure biomarkers) or the magnitude of the organism's response (effect biomarkers). They are considered early warning signals because changes at the lower levels of biological organization (e.g. molecule, cell, or tissue) can predict changes at the higher levels (e.g. population, community, or ecosystem). To date, various petroleum hydrocarbon sensitive biomarkers, e.g. antioxidant enzymes, have been identified $^{12-15}$. These biomarkers have been employed as ecotoxicological tools for post-oil spill evaluation of fish and bivalve populations ${ }^{16}$. However, given that more than one biomarker response is generally observed after exposure to toxic compounds, individual biomarkers do not entirely reflect the biological responses of contaminant-induced stress. Therefore, several biomarkers are combined to give the integrated biomarker response (IBR) index ${ }^{17,18}$. The integrated biomarker response method is currently regarded as the best available approach for monitoring the effects of pollution in marine ecosystems ${ }^{19,20}$. In particular, Marigómez et al. ${ }^{21}$ attempted to assess marine ecosystem health using the integrated biomarker response approach after an oil spill. The results suggested that the integrated biomarker response method describing pollution-induced stress constitutes a useful tool for environmental researchers and scientists. However, the toxicological effects of water-soluble fraction of crude oil with environmental relevant concentrations in clams (Ruditapes philippinarum) using the integrated biomarker response method under controllable laboratory conditions have not been investigated.

Bivalves have long been recognized as valuable indicators of environmental pollutants because of their advantageous characteristics (e.g. they have powerful bioaccumulation abilities, they are highly sensitive to pollutants because of their unique filter-feeding habit and they are easily cultured in the laboratory $)^{22}$. Clam is an important class of the bivalve. Furthermore, the hepatopancreas is a major site of toxicant storage, uptake and ROS-generating biotransformation enzymes $^{23}$. Thus, the aim of the present study is: (1) to evaluate the responses of five biomarkers (superoxide dismutase, catalase, glutathione peroxidase, glutathione S-transferases and peroxidase) in the hepatopancreas of clams (Ruditapes philippinarum) after short- (1, 2 and 4 days) and long-term ( 8 and 15 days) exposure to environmentally relevant concentrations of crude oil water-soluble fraction under laboratory conditions, (2) to produce the integrated biomarker response index and star plot for interpretation of the biomarkers responses and (3) to address the relationship between the integrated biomarker response values and water-soluble fraction concentration. The present study expands our current knowledge of petroleum-induced stress biomarkers in marine organisms and provides a useful tool for evaluating the ecological effects of petroleum hydrocarbons on the marine environment.

\section{EXPERIMENTAL}

Test clams: Clams Ruditapes philippinarum (body length: $3.02 \pm 0.12 \mathrm{~cm}$; body weight: $6.24 \pm 0.21 \mathrm{~g}$ ) were purchased from Jiaozhou Bay, Shandong, P.R. China. They were taken to the laboratory and cultured in a $500 \mathrm{~L}$ glass tank filled with filtered seawater (acclimatization conditions: temperature = $21.0 \pm 0.4{ }^{\circ} \mathrm{C}$; salinity $=29.1 \pm 0.2 ; \mathrm{pH}=7.85 \pm 0.03$; light: dark $=16 \mathrm{~h}: 8 \mathrm{~h}$ ) for 14 days prior to exposure to fully ensure environmental adaptation. The clams were fed twice daily with Chlorella sp. $\left(3 \times 10^{6} \mathrm{ind} / \mathrm{mL}\right)$. No medication was administered and no mortality was detected during the acclimation period. The clams were starved for at least $24 \mathrm{~h}$ to ensure complete gut clearance prior to the exposure experiments.

Preparation of crude oil water-soluble fraction: It is well known that the crude oil contain hundreds of compounds, such as alkane, aromatic hydrocarbons and naphthenic hydrocarbons. Specifically, the shengli crude oil, obtained from the shengli oil field (China), was composed primarily of aromatic hydrocarbons and naphthenic hydrocarbons. The water-soluble fraction was prepared from Shengli crude oil and stored at $4{ }^{\circ} \mathrm{C}$. The crude oil and filtered seawater in a ratio of $1: 100$ (v/v) were stirred at low speed for $24 \mathrm{~h}$ using a mechanical stirrer and then allowed to settle for $48 \mathrm{~h}^{24}$. water-soluble fraction was collected using the bottom drain. Stock solutions of water-soluble fraction were kept in $5 \mathrm{~L}$ brown glass bottles at $4{ }^{\circ} \mathrm{C}$. During the experiments, fresh water-soluble fraction was prepared every 2 days.

Chemical analyses: Water-soluble fraction concentrations were determined using a fluorescence spectrophotometer (Hitachi, F-4600, Japan) at $360 \mathrm{~nm}$ emission wavelength, according to the national specification for marine monitoring (GB17378.4-2007, China). Petroleum quantification was based on calibration curves of standard petroleum hydrocarbon solution. The standard solutions were freshly prepared and the standard calibration curves with $r^{2}>0.996$ were attained each time. The petroleum hydrocarbon detection limit was $9.2 \times 10^{-3} \mathrm{mg} / \mathrm{L}$.

Exposure experiment: To avoid any effects from chemicals other than the test compounds, all exposure systems were made of glass. Fifty clams were placed in $70 \mathrm{~L}$ glass beakers filled with filtered seawater in a triplicate design and exposed to nominal concentrations of $0.1,0.2,0.4,0.8,1.6$ and $3.2 \mathrm{mg} / \mathrm{L}$ petroleum hydrocarbon along with a control group in clean seawater for a period of 15 days. Each treatment was conducted in triplicate. The exposure concentrations were designed to measure the sub-lethal effect over the experimental period rather than mortality. In addition, the concentrations selected were comparable to post-oil spill conditions. The exposure solution was completely replaced daily to maintain a relatively stable aqueous phase water-soluble fraction concentration. The clams were held in each exposure tank under a 16h:8h (light: dark) photoperiod and were maintained at a water temperature of $21 \pm 0.4{ }^{\circ} \mathrm{C}, \mathrm{pH}=7.85 \pm 0.03$ and dissolved oxygen level of $7.5 \pm 0.5 \mathrm{mg} / \mathrm{L}$. The clams were fed daily with Chlorella 
sp. during exposure experiments. Six clams in each group were sampled after 1, 2, 4, 8 and 15 days. Short- (1, 2 and 4 days) and long-term ( 8 and 15 days) exposure experiments were conducted to assess multi-biomarker responses to petroleum hydrocarbons. At the end of each exposure period, hepatopancreas tissue was collected from four random clams, washed with physiological saline $(0.9 \%, \mathrm{NaCl})$, immediately frozen in nitrogen and stored at $-80{ }^{\circ} \mathrm{C}$ until subsequent analysis.

Enzyme activity assays: All of the enzyme activity assays were conducted within 1 day of sample preparation. The frozen hepatopancreas (about $0.6 \mathrm{~g}$ ) were homogenized in cold phosphate buffer $\left(0.1 \mathrm{M}, \mathrm{pH} 7.2,0.1 \%\right.$ Triton X-100) at $4{ }^{\circ} \mathrm{C}$ on ice using a glass tissue homogenizer. The homogenate was centrifuged at $3500 \mathrm{r} / \mathrm{min}$ for $10 \mathrm{~min}$ at $4{ }^{\circ} \mathrm{C}$ and the resulting supernatant was kept in $0.5 \mathrm{~mL}$ aliquots to analyze enzyme activity.

Superoxide dismutase, catalase, glutathione peroxidase, glutathione S-transferase and peroxidase activities were measured in the hepatopancreas fractions. Superoxide dismutase activity was determined based on its ability to inhibit the reduction of nitroblue tetrazolium (NBT) by superoxide radicals generated with xanthine/xanthine oxidase. One unit of superoxide dismutase activity (U) is defined as the amount of protein that inhibits the rate of NBT reduction by $50 \%{ }^{25}$. Catalase activity was determined using the method of Claiborne ${ }^{26}$ by measuring the initial rate of decrease in absorbance at $240 \mathrm{~nm}$ as a consequence of $\mathrm{H}_{2} \mathrm{O}_{2}$ consumption over $1 \mathrm{~min}$. Glutathione peroxidase activity was assessed using $\mathrm{H}_{2} \mathrm{O}_{2}$ as a substrate according to Drotar et al. ${ }^{27}$. This method is based on the oxidation of GSH by $\mathrm{H}_{2} \mathrm{O}_{2}$ via glutathione peroxidase. Glutathione Stransferases activity was determined at $340 \mathrm{~nm}$ as described by Habig et al. ${ }^{28}$, where 1-chloro-2, 4-dinitrobenzene was used as a substrate. Peroxidase activity was assayed using guaiacol as a hydrogen donor by measuring the change at $470 \mathrm{~nm}$ over $1 \mathrm{~min}$ as previously reported by Chance and Maehly ${ }^{29}$. Protein concentrations in the hepatopancreas were determined at 595 $\mathrm{nm}$ using the method developed by Bradford ${ }^{30}$, with bovine serum albumin as the standard.

Integrated biomarker responses (IBR): The integrated biomarker responses (IBR) were evaluated according to Beliaeff and Burgeot ${ }^{17}$, with modification. The calculation method was based on the relative differences between the biomarkers in each given data set. Thus, the integrated biomarker response index was computed by summing-up triangular star plot areas (a simple multivariate graphic method) for each of the two neighboring biomarkers in a given data set, according to the following procedure: (1) calculation of the mean and standard deviation for each biomarker; (2) standardization of data for each sample: $\mathrm{Y}=(\mathrm{x}-\mathrm{m}) / \mathrm{s}$; where $\mathrm{Y}$ is standardized value of the biomarker; $\mathrm{x}$ is the value of each biomarker response; $\mathrm{m}$ is mean value of the biomarker; $s$ is the standard deviation of the biomarker; (3) using the standardized data, $Z$ was computed as $+Y$ in the case of an activation and $-Y$ in the case of an inhibition. The score ( $\mathrm{S}$ ) was computed as $\mathrm{S}=\mathrm{Z}+$ Iminl, where $\mathrm{S} \geq 0$ and Iminl is the absolute minimum value obtained from $\mathrm{Y}$ for each biomarker.

Star plots were used to visualize the score results. A star plot radical coordinate represents the score of a given biomarker at a given treatment. If $\mathrm{S}_{\mathrm{i}}$ and $\mathrm{S}_{\mathrm{i}+1}$ are two consecutive clockwise scores of a given star plot and $\mathrm{n}$ is the number of radii corresponding to the biomarkers used in the treatments, the integrated biomarker response value obtained from the sum of the triangular areas can be calculated with the following equation:

$$
\mathrm{IBR}=\sum_{\mathrm{i}}^{\mathrm{n}} \frac{\left(\mathrm{S}_{\mathrm{i}} \mathrm{S}_{\mathrm{i}+1}\right)}{2}
$$

Statistical analysis: Statistical analyses were carried out using the Statistical Package for the Social Sciences (SPSS) version 13. One-way analysis of variance (ANOVA) was used to compare the variables between the treatments and control groups. The data met the assumptions of ANOVA. Tukey's range test was conducted to identify significant differences among groups. The significance level was $\mathrm{p}<0.05$.

\section{RESULTS AND DISCUSSION}

Exposure concentration: The nominal concentrations $(0.1,0.2,0.4,0.8,1.6$ and $3.2 \mathrm{mg} / \mathrm{L})$ were designed based on two factors. Firstly, the exposure experiment focused on the sub-lethal effects in the clams. According to a previous experiment, the $\mathrm{LC}_{50}$ value of the Shengli crude oil was $>3.2 \mathrm{mg} / \mathrm{L}$ (unpublished data). Secondly, the clams examined in the present study were exposed to environmentally relevant postoil spill concentrations. Seawater petroleum hydrocarbons after the Hebei Spirit oil spill ranged from 1.5 to $7310 \mu \mathrm{g} / \mathrm{L}^{31}$. During the exposure period, the petroleum hydrocarbons in the test solution ranged from 0.09 to $3.16 \mathrm{mg} / \mathrm{L}$ (Table-1). The measured concentrations were much lower than the nominal concentrations, mostly like because of absorption of the chemicals onto the walls of the tanks. The volatilization or degradation of petroleum hydrocarbons may be an important factor. Li et al..$^{32}$

\begin{tabular}{|c|c|c|c|c|c|c|c|}
\hline \multicolumn{8}{|c|}{$\begin{array}{l}\text { TABLE-1 } \\
\text { MEASURED CONCENTRATION OF WATER-SOLUBLE FRACTION (WSF) } \\
\text { OF CRUDE OIL IN THE TEST SOLUTION DURING THE EXPOSURE PERIOD }\end{array}$} \\
\hline \multirow{2}{*}{$\begin{array}{c}\text { Nominal concentration } \\
(\mathrm{mg} / \mathrm{L})\end{array}$} & \multicolumn{6}{|c|}{ Measured concentration $(\mathrm{mg} / \mathrm{L})$} & \\
\hline & 0 day & 1 day & 2 days & 4 days & 8 days & 15 days & Mean \pm SD \\
\hline Control & ND & ND & ND & ND & ND & ND & ND \\
\hline 0.1 & 0.11 & 0.11 & 0.08 & 0.10 & 0.09 & 0.07 & $0.09 \pm 0.02$ \\
\hline 0.2 & 0.21 & 0.21 & 0.17 & 0.18 & 0.19 & 0.16 & $0.19 \pm 0.02$ \\
\hline 0.4 & 0.43 & 0.41 & 0.37 & 0.38 & 0.36 & 0.37 & $0.39 \pm 0.03$ \\
\hline 0.8 & 0.84 & 0.83 & 0.76 & 0.74 & 0.75 & 0.76 & $0.78 \pm 0.04$ \\
\hline 1.6 & 1.62 & 1.61 & 1.57 & 1.54 & 1.53 & 1.52 & $1.57 \pm 0.04$ \\
\hline 3.2 & 3.22 & 3.21 & 3.18 & 3.12 & 3.11 & 3.10 & $3.16 \pm 0.05$ \\
\hline
\end{tabular}

Note: ND means not detected 
reported that the contribution to self-purification of petroleum hydrocarbons by volatilization and biodegradation accounted for 48 and $28 \%$, respectively.

Clam biomarker responses: Superoxide dismutase is the only antioxidant enzyme that uses the radical as a substrate and is responsible for catalyzing the dismutation of the highly superoxide radical $* \mathrm{O}_{2}^{-}$to $\mathrm{H}_{2} \mathrm{O}_{2}$ and $\mathrm{O}_{2}$. The depletion of superoxide dismutase activity is used as an indication of free radical scavenging ability, showing that the antioxidant defense system is overwhelmed by $\operatorname{ROS}^{33}$. In the present study, superoxide dismutase activity in the hepatopancreas is shown in Fig. 2a, where we can see that the superoxide dismutase activity varied with exposure concentration and time. During the exposure period, there were no significant differences in superoxide dismutase activity between the lower concentration treatments $(0.1,0.2$ and $0.4 \mathrm{mg} / \mathrm{L})$ and the control group $(\mathrm{p}>$ $0.05)$, suggesting that the ROS produced by petroleum hydrocarbon cannot significantly induce the response of superoxide dismutase due to lower exposure concentrations. After 1 day, a significant increase in superoxide dismutase activity was observed in response to higher petroleum treatments $(0.8,1.6$ and $3.2 \mathrm{mg} / \mathrm{L}$ ) compared with the control group ( $\mathrm{p}<0.05)$, showing a greater concentration-dependent response than those of the lower petroleum concentration treatments $(0.1,0.2$ and $0.4 \mathrm{mg} / \mathrm{L}$ ), which suggests increasing superoxide dismutase activity to detoxify superoxide radical ${ }^{*} \mathrm{O}_{2}{ }^{-}$. However, superoxide dismutase activity decreased significantly after 4 and 8 days exposure in higher petroleum treatments $(0.8,1.6$ and $3.2 \mathrm{mg} / \mathrm{L}$ ) as compared with controls, suggesting the enhanced ROS level had exceeded the eliminating ability of the antioxidant enzyme. These results are in accordance with Lavarias et $a l^{7}$. They reported that superoxide dismutase activity in hepatopancreas of adult prawns (Macrobrachium borellii) showed a significant increase in activity (43\%) after only 7 days of exposure to $0.6 \mathrm{mg} / \mathrm{L}$ water-soluble fraction. In the gills, superoxide dismutase activity was not altered after watersoluble fraction exposure with values of $0.74 \pm 0.20$ (controls) and $0.92 \pm 0.39 \mathrm{U} / \mathrm{min} \mathrm{mg}$ protein (treated) ${ }^{7}$. Similarly, when the tadpoles were exposed to water-soluble fraction from Bonny Light crude oil, increased superoxide dismutase activity at lower concentrations and conversely decreased enzyme activity at higher doses was observed by Eriyamremu et al $^{34}$. According to Sun and Zhou ${ }^{35}$, the activity of superoxide dismutase in the polychaete $N$. diversicolour exposed to petroleum hydrocarbons increased after 6 days exposure and then decreased after 9 days. Therefore, superoxide dismutase can protect the organisms from oxidative damages by scavenging the superoxide radical $* \mathrm{O}_{2}^{-}$.

Catalase is a key nonspecific antioxidant enzyme that can remove the resulting $\mathrm{H}_{2} \mathrm{O}_{2}$, which is then converted to $\mathrm{H}_{2} \mathrm{O}$ and $\mathrm{O}_{2}$. Glutathione peroxidase is an important peroxidase playing a key role in reducing lipid hydroperoxides and $\mathrm{H}_{2} \mathrm{O}_{2}$ to non-toxic products at the expense of glutathione. Elevation of catalase and glutathione peroxidase activity could protect the organism from oxidative damage. In this study, catalase and glutathione peroxidase activity in the hepatopancreas of clams fluctuated with water-soluble fraction concentration and exposure time (Fig. 2b and c). In 0.1 and $0.2 \mathrm{mg} / \mathrm{L}$ treatment groups, higher catalase activity on 2 and 4 day exposure was observed compared with control level $(\mathrm{p}<0.05)$ and in 0.8 , 1.6 and $3.2 \mathrm{mg} / \mathrm{L}$ treatments, catalase activity was significantly induced on 1 and 2 day exposure $(\mathrm{p}<0.05)$ and then decreasing with the increasing exposure time. In general, glutathione peroxidase activity exhibited a pattern with a reduction at lower concentrations $(0.1,0.2$ and $0.4 \mathrm{mg} / \mathrm{L})$ and a significant increase at higher concentrations $(1.6$ and $3.2 \mathrm{mg} / \mathrm{L})(\mathrm{p}<0.05)$. Variation of catalase and glutathione peroxidase activities were not similar with superoxide dismutase activities, which could be explained that the dismutation of superoxide radical $* \mathrm{O}_{2}^{-}$ was not the only source of $\mathrm{H}_{2} \mathrm{O}_{2}$ and the redundant that could also be generated by amino acids or cytochrome $\mathrm{P} 450$ enzymes activation ${ }^{36}$. In previous studies, catalase activity was induced in response to exposure to polycyclic aromatic hydrocarbonor polychloroinated biphenyl-contaminated sediments in fish ${ }^{37}$ and marine mussels ${ }^{38}$. It is found from our study that the responses of catalase were more sensitive than glutathione peroxidase. It is worth noting that glutathione peroxidase plays an important role in $\mathrm{H}_{2} \mathrm{O}_{2}$ detoxification in vertebrates, while catalase fulfills this role in invertebrates ${ }^{39}$.

Glutathione S-transferases, belonging to the phase II enzymes, plays a role in the detoxification of oxidative stress products and the conjugation of glutathione to xenobiotic metabolites, thus facilitating their excretion. In the present study, glutathione S-transferases activity variation in the hepatopancreas is shown in Fig. 1d. When exposed for 4 days, glutathione S-transferases activity at $0.8,1.6$ and $3.2 \mathrm{mg} / \mathrm{L}$ differed significantly from that of the control, decreasing to $71.83,69.33$ and $71.43 \%$ of the control level, respectively $(\mathrm{p}<0.05)$. After 8 days, glutathione $\mathrm{S}$-transferases activity had significantly increased compared with the controls exposed to the lower concentrations (129.42, 149.69 and $139.11 \%$ of the control level at $0.1,0.2$ and $0.4 \mathrm{mg} / \mathrm{L}$ treatments, respectively. $\mathrm{p}<0.05)$. Similarly, Zhang et al. ${ }^{40}$ observed that in goldfish (Carassius auratus), exposure to diesel oil watersoluble fraction resulted in an increase in glutathione S-transferases activity at higher concentrations of polycyclic aromatic hydrocarbons compared with that at lower concentrations. In addition, our results agree with reports in freshwater crayfish, Eriocheir japonicus, showing higher levels of glutathione S-transferases activity when treated with polycyclic aromatic hydrocarbon and polychlorinated biphenyls ${ }^{41}$.

Peroxidase is the key enzyme in antioxidant defense systems converting $\mathrm{H}_{2} \mathrm{O}_{2}$ free radicals to water and oxygen. In the present study (Fig. 1e), after 2 days, the highest peroxidase activity was observed at the highest concentration $(3.2 \mathrm{mg} / \mathrm{L})$, with an increase of $130.59 \%$ of the control level $(\mathrm{p}<0.05)$, suggesting that the clams has adapted to the stress of petroleum hydrocarbon after 2 days exposure and can protect itself from the oxidative damage. When exposed for 8 days, peroxidase activity at $0.4,0.8,1.6$ and $3.2 \mathrm{mg} / \mathrm{L}$ decreased to $79.99,75.00$, 69.61 and $72.83 \%$ of the control level, respectively $(\mathrm{p}<0.05)$, suggesting that there was a precarious state and potential adverse effects by petroleum hydrocarbon. These results are consistent with the literature since Sun et al. ${ }^{42}$ showed that the peroxidase activity of polychaete (Perinereis aibuhitensis) petroleum hydrocarbons treatment groups was slightly inhibited for the duration of exposure in comparison to the control. Moreover, the decrease in peroxidase activity in the 

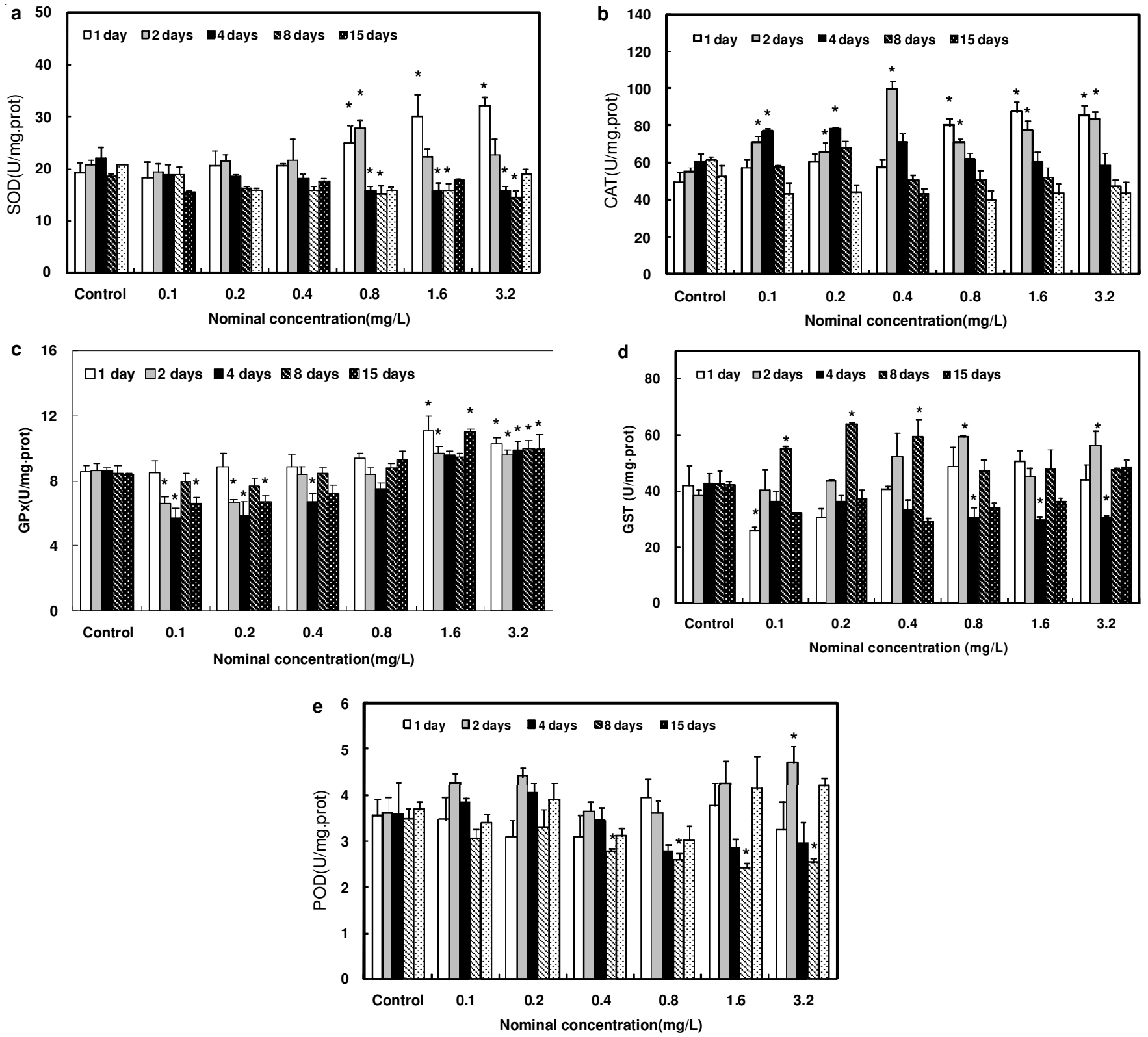

Fig.1. Biomarker responses exposed to Water-soluble fraction (WSF) of petroleum: (a) superoxide dismutase (SOD) activity; (b) catalase (CAT) activity; (c) glutathione peroxidase (GPx) activity; (d) Glutathione S-transferases (GST) activity; (e) peroxidase (POD) activity. The error bar represents the standard deviations, and the asterisk indicates the significant difference between the control and the treatments $(\mathrm{p}<0.05)$.

polychaete Nereis diversicolour reflected oxidative stress induced by petroleum hydrocarbons ${ }^{35}$.

Integrated biomarker responses: As shown in Fig. 1, the water-soluble fraction biomarker responses in clams varied with time and dosage. Some biomarkers were induced, while others were inhibited. Since individual biomarker results are often difficult to interpret, it was necessary to use multi-biomarkers to evaluate pollutant-induced stress. To demonstrate the contribution of the each biomarker to the integrated biomarker response index, the enzyme responses using the integrated biomarker response calculation method according to Beliaeff and Burgeot ${ }^{17}$ are standardized in Table-2 and visualized in Fig. 2. During the exposure period, maximum values represented the highest responses of each biomarker (1 and 2 days for superoxide dismutase, 4 days for catalase, 8 days for glutathione peroxidase and 15 days for peroxidase), while minimum values revealed the lowest responses for each biomarker (1 day for glutathione S-transferases, 2 days for glutathione peroxidase, 4 and 8 days for superoxide dismutase and 15 days for catalase). The results suggest that in a short exposure time, superoxide dismutase for 1 and 2 days and catalase for 4 days were the dominant enzymes in response to petroleum hydrocarbons. In this sense, the superoxide dismutase and catalase activity in clams Ruditapes philippinarum can be considered as a sensitive antioxidant biomarkers to response to the stress of petroleum hydrocarbon. These findings may be explained by the characteristics of superoxide dismutase and catalase, which play important roles in removing superoxide radical and $\mathrm{H}_{2} \mathrm{O}_{2}$. Similar results were reported in crustaceans (Macrobrachium borellii) exposed to petroleum water-soluble fraction ${ }^{17}$. Other authors have also found that increments of superoxide dismutase and catalase activity in 

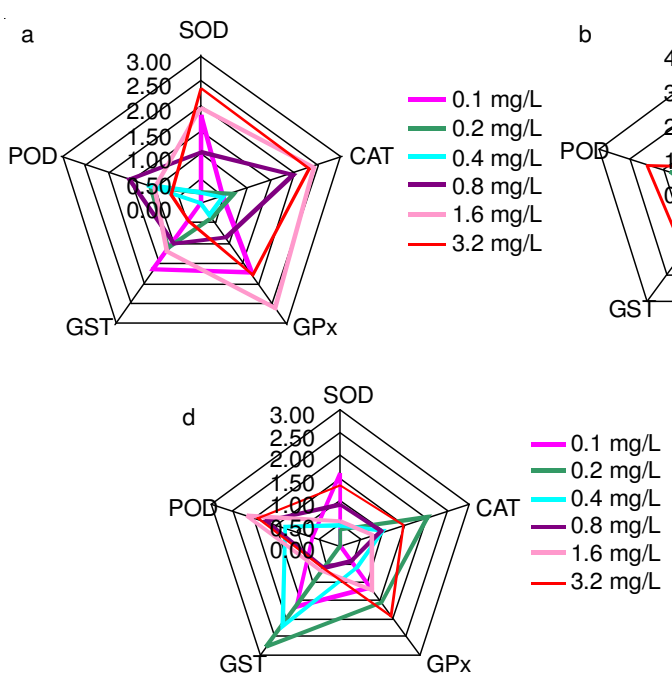
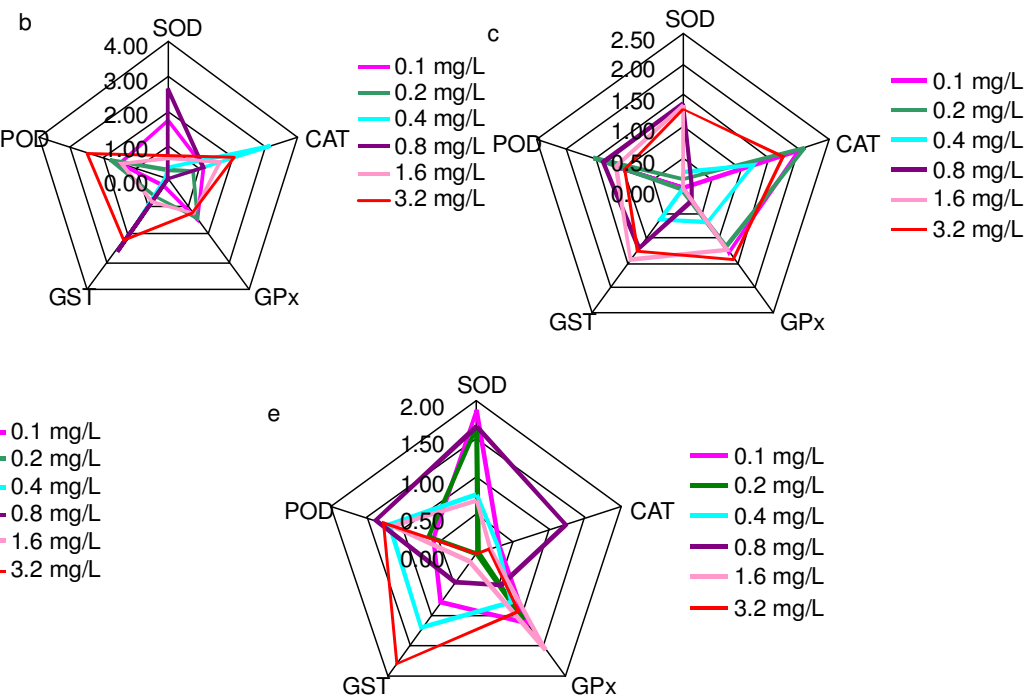

Fig. 2. Star plots for biomarker responses in ruditapes philippinarum exposed to water-soluble fraction (WSF) for (a) 1 day, (b) 2 days, (c) 4 days, (d) 8 days, and (e) 15 days $(\mathrm{SOD}=$ Superoxide dismutase CAT = Catalase GPx = Glutathione peroxidase; GST = Glutathione S-transferases; POD = Peroxidase)

TABLE-2

STANDARDIZED BIOMARKER RESPONSES (S VALUES) IN Ruditapes philippinarum EXPOSED TO WATER-SOLUBLE FRACTION (WSF) OF PETROLEUM HYDROCARBONS AND THE CORRESPONDING INTEGRATED BIOMARKER RESPONSE INTEGRATED BIOMARKER RESPONSE (IBR) VALUES

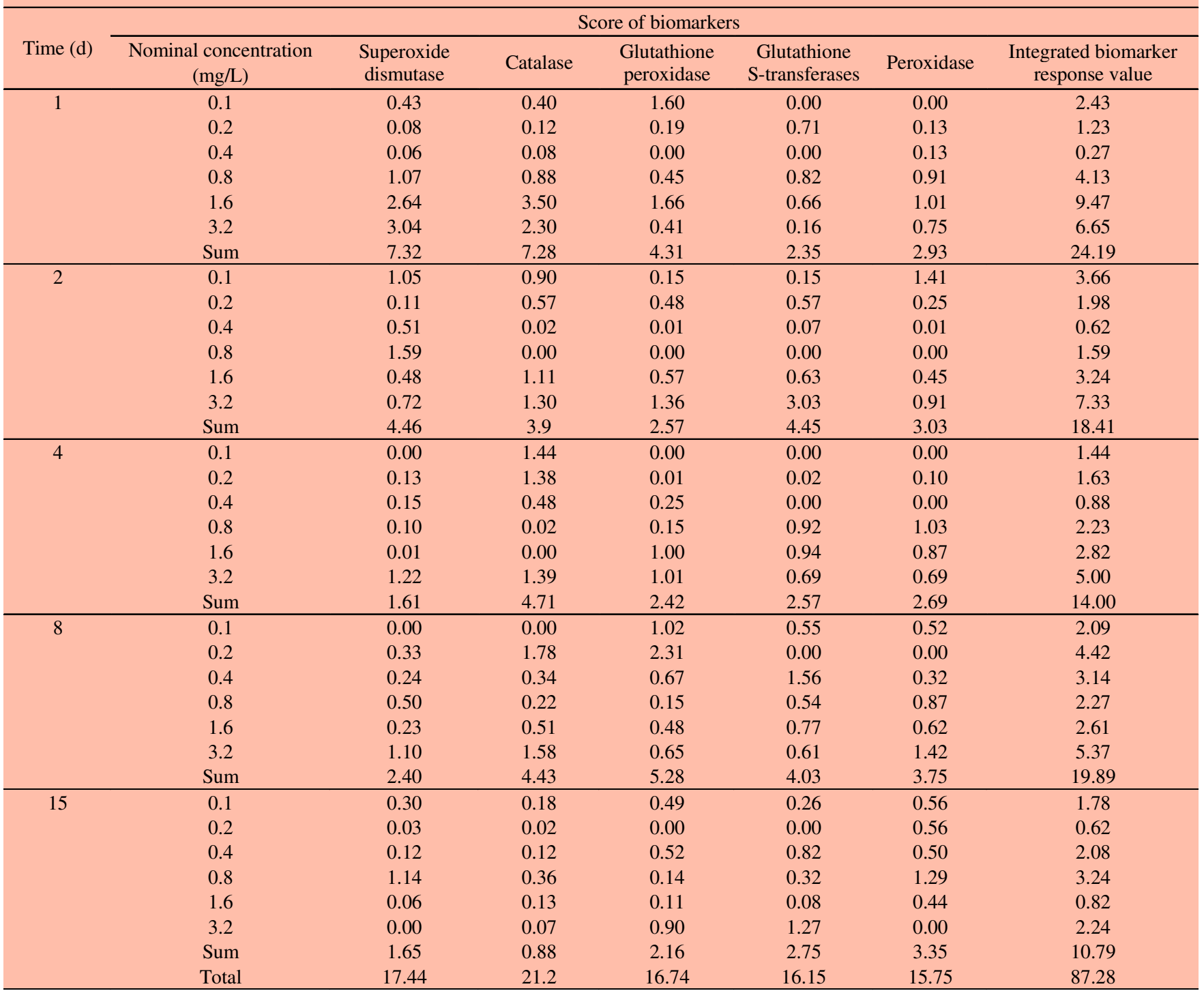


clams exposed to polycyclic aromatic hydrocarbon were positively correlated with whole body tissue polycyclic aromatic hydrocarbon ${ }^{38,43}$. However, Milinkovitch et al $^{44}$ recorded no significant differences between exposure conditions for the antioxidant enzymes superoxide dismutase, catalase, glutathione peroxidase and glutathione S-transferases.

The relationship between integrated biomarker response values and petroleum water-soluble fraction concentrations is presented in Fig. 3. After 1, 2 and 4 days, the integrated biomarker response values were positively correlated with petroleum concentration $\left(r^{2}=0.521, r^{2}=0.815\right.$ and $r^{2}=0.935$, respectively). In contrast, there was poor correlation between the integrated biomarker response values and petroleum concentration after 8 or 15 days $\left(r^{2}=0.357\right.$ and $r^{2}=0.024$, respectively). This is in agreement with Kim et $a .^{31}$, who
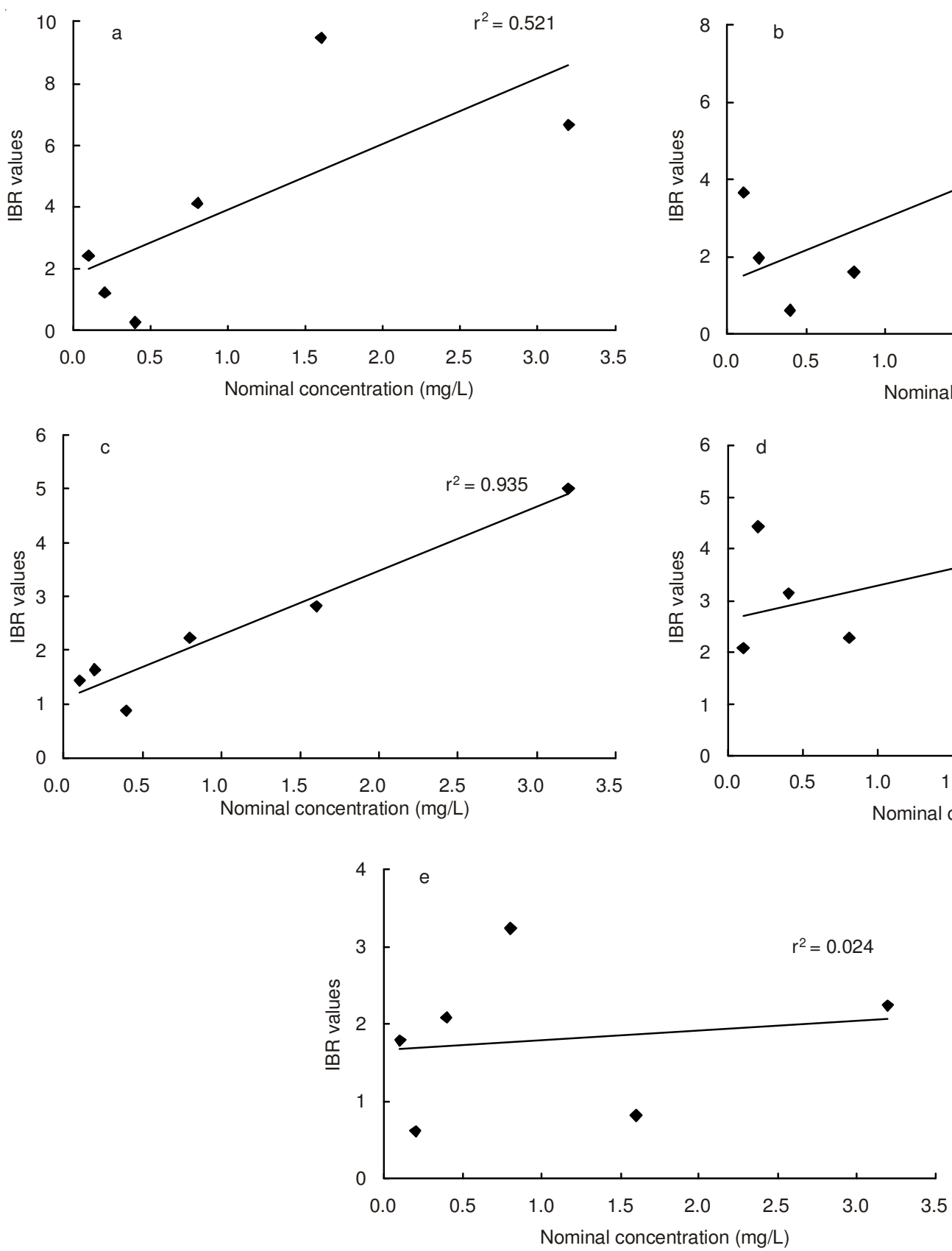

Fig. 3. Correlation between integrated biomarker response (IBR) values and different Water-soluble fraction (WSF) concentrations after short- and long-

term exposure. (a) 1 day; (b) 2 days; (c) 4 days; (d) 8 days; (e) 15 days demonstrated that integrated biomarker response values were positively correlated with $\mathrm{Cu}$ and $\mathrm{BaP}$ concentration and that the correlations were enhanced after 4 days of exposure $\left(r^{2}=\right.$ 0.849 and 0.945 , respectively) compared with 14 days $\left(r^{2}=\right.$ 0.412 and 0.634 , respectively). In addition, the integrated biomarker response values were positively correlated with the logarithmic concentrations of perfluorooctanoic acid (PFOA) and perfluorooctane sulfonate (PFOS) ${ }^{45}$. These findings indicate that an integrated evaluation of biochemical biomarker responses may be useful in a quantitative monitoring method in short-term toxicity assessments. Moreover, the integrated biomarker response approach has been applied for comprehensive environmental quality evaluation in the field. In Baltic Sea eelpout (Zoarces viviparus) and mussel (Mytilus sp.) populations, integrated biomarker response was positively
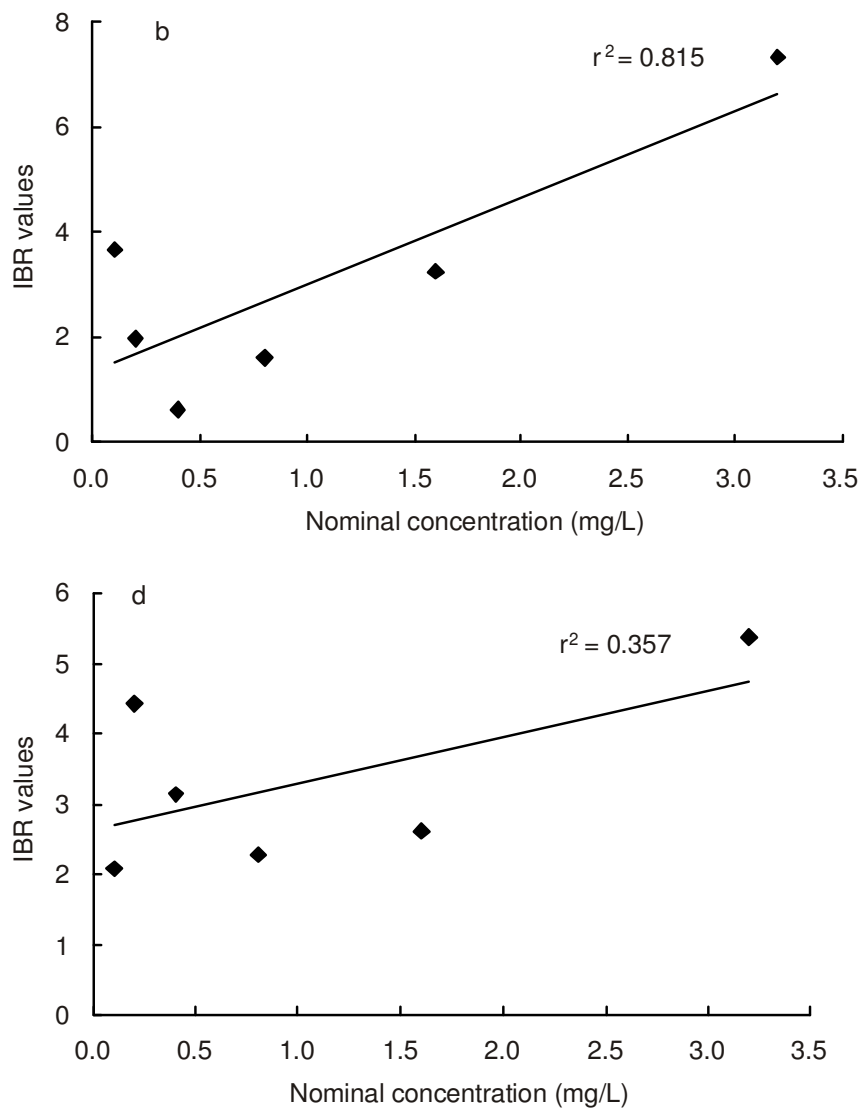

$r^{2}=0.024$ 
correlated with organochlorine compound levels in body tissues ${ }^{18}$. In mussels (Mytilus galloprovincialis) caged at several stations in the Bay of Cannes, Dagnino et al. ${ }^{46}$ found good correlation between integrated biomarker response and tissue $\mathrm{Cu}$ and polychlorinated biphenyl concentrations, but not with polycyclic aromatic hydrocarbon concentrations. In goldfish (Carassius auratus) transplanted in Taihou lake (China), there was a visual correlation between the polychlorinated biphenyl and the OCP gradient measured in the sediments and integrated biomarker response variation ${ }^{47}$.

According to the above study, the marine system contamination assessment should not only focus on the individual biomarker but on the integrated biomarker responses of organisms under the environmental stress. Furthermore, except the antioxidant enzymes, the other biomarker such as lysosomal stability, lipid peroxidation, DNA damage and so on, should be considered in the evaluating system of integrated biological effects in future study and then the discriminatory power of the adopted multi-biomarker strategy can be improved.

\section{Conclusion}

In conclusion, we evaluated the biochemical responses of a representative marine clams following exposure to an environmentally relevant contaminant adopting the integrated biomarker approach. The integrated biomarker response method could serve as an effective tool to determine the harmful effects of pollutants on marine biota. However, long-term exposure did not result in an effective response in the biological biomarkers. These findings suggest that the integrated biomarker response approach could provide evidence for assessing environmental health in terms of risk assessment. Furthermore, studies of long-term exposure over 15 days and depuration after exposure are needed to improve our mechanistic knowledge about the effects of pollutants in environmental relevant concentration through various levels of biological responses.

\section{ACKNOWLEDGEMENTS}

The study was supported by Shandong Provincial Natural Science Foundation, China (ZR2010CQ023), Key Laboratory of Marine Spill Oil Identification and Damage Assessment Technology, China (201111) and Special Scientific Research Funds for Central Non-profit Institute, Chinese Academy of Fishery Sciences (2012A0202).

\section{REFERENCES}

1. A.V. Botello, F.S. Villanueva and G.G. Diaz, Rev. Environ. Contam. Toxicol., 153, 91 (1997).

2. E. Peña, J.E. Conde and F.G. Montelongo, Arch. Environ. Contam. Toxicol., 31, 444 (1996).

3. P.J. Ralph and M.D. Burchett, Mar. Pollut. Bull., 36, 429 (1998).

4. A. Arukwe, T. Nordtug, T.M. Kortner, A.S. Mortensen and O.G. Brakstad, Environ. Res., 107, 362 (2008)

5. H. Heras, R.G. Ackman and E.J. Macpherson, Mar. Pollut. Bull., 24, 310 (1992).

6. S. Lavarias, H. Heras and R.J. Pollero, Arch. Environ. Contam. Toxicol., 47, 215 (2004).

7. S. Lavarías, H. Heras, N. Pedrini, H. Tournier and M. Ansaldo, Comp. Biochem. Physiol. C, 153, 415 (2011).

8. D.R. Livingstone, Rev. Med. Vet. (Toulouse), 154, 427 (2003).

9. L.M. Gaetke and C.K. Chow, Toxicology, 189, 147 (2003).
10. S. Rama Devi and M.N.V. Prasad, Plant Sci., 138, 157 (1998).

11. J.E.J. Weckx and H.M.M. Clijsters, Physiol. Plant., 96, 506 (1996).

12. J.A. de Knecht, G.J. Stroomberg, C. Tump, M. Helms, R.A. Verweij, J. Commandeur, C.A.M. van Gestel and N.M. van Straalen, Environ. Toxicol. Chem., 20, 1457 (2001).

13. C. Morales-Caselles, M.L. Martin-Diaz, I. Riba, C. Sarasquete and T.A. DelValls, Chemosphere, 72, 819 (2008).

14. S. Niyogi, S. Biswas, S. Sarker and A.G. Datta, Sci. Total Environ., 281, 237 (2001).

15. A. Orbea, M. Ortiz-Zarragoitia, M. Sole, C. Porte and M.P. Cajaraville, Aquat. Toxicol., 58, 75 (2002).

16. C. Martinez-Gomez, J.A. Campillo, J. Benedicto, B. Fernandez, J. Valdes, I. Garcia and F. Sanchez, Mar. Pollut. Bull., 53, 305 (2006).

17. B. Beliaeff and T. Burgeot, Environ. Toxicol. Chem., 21, 1316 (2002).

18. K. Broeg and K.K. Lehtonen, Mar. Pollut. Bull., 53, 508 (2006).

19. S. Brooks, C. Harman, B. Zaldibar, U. Izagirre, T. Glette and I. Marigomez, Mar. Pollut. Bull., 62, 327 (2011).

20. F. Meng, Z. Wang, F. Cheng, X. Du, W. Fu, Q. Wang, X. Yi, Y. Li and Y. Zhou, Mar. Environ. Res., 85, 64 (2013).

21. I. Marigómez, L. Garmendia, M. Soto, A. Orbea, U. Izagirre and M. Cajaraville, Ecotoxicology, 22, 486 (2013).

22. K. Ramu, N. Kajiwara, A. Sudaryanto, T. Isobe, S. Takahashi, A. Subramanian, D. Ueno, G.J. Zheng, P.K.S. Lam, H. Takada, M.P. Zakaria, P.H. Viet, M. Prudente, T.S. Tana and S. Tanabe, Environ. Sci. Technol., 41, 4580 (2007).

23. E.I. Cengiz and E. Unlu, Environ. Toxicol. Pharmacol., 21, 246 (2006).

24. H. Heras, R.G. Ackman and E.J. Macpherson, Mar. Pollut. Bull., 24, 310 (1992).

25. Y. Sun, L.W. Oberley and Y. Li, Clin. Chem., 34, 497 (1988).

26. A. Claiborne, in ed.: R.A. Greenwald, Catalase Activity, CRC Handbook of Methods for Oxygen Radical Research, CRC Press, Boca Raton, FL, pp. 283-284 (1985).

27. A. Drotar, P. Phelps and R. Fall, Plant Sci., 42, 35 (1985).

28. W.H. Habig, M.J. Pabst and W.B. Jakoby, J. Biol. Chem., 249, 7130 (1974).

29. B. Chance and A.C. Maehly, Methods Enzymol., 2, 764 (1955).

30. M.M. Bradford, Anal. Biochem., 72, 248 (1976).

31. M. Kim, S.H. Hong, J. Won, U.H. Yim, J.H. Jung, S.Y. Ha, J.G. An, C. Joo, E. Kim, G.M. Han, S. Baek, H.W. Choi and W.J. Shim, Water Res., 47, 758 (2013).

32. K.Q. Li, Y. Su, J. Ying, X.L. Wang and J.B. Mu, J. Ocean Univ. China, 12, 70 (2013).

33. R. van der Oost, J. Beyer and N.P. Vermeulen, Environ. Toxicol. Pharmacol., 13, 57 (2003).

34. G.E. Eriyamremu, V.E. Osagie, S.E. Omoregie and C.O. Omofoma, Ecotoxicol. Environ. Saf., 71, 284 (2008).

35. F.H. Sun and Q.X. Zhou, Ecotoxicol. Environ. Saf., 70, 106 (2008).

36. J. Remacle, D. Lambert, M. Raes, E. Pigeolet, C. Michiels and O. Toussaint, Biochem. J., 286, 41 (1992).

37. A. Rodríguez-Ariza, J. Peinado, C. Pueyo and J. López-Barea, Can. J. Fish. Aquat. Sci., 50, 2568 (1993).

38. C. Porte, M. Sole, J. Albaiges and D.R. Livingstone, Comp. Biochem. Physiol. C, 100, 183 (1991).

39. D.R. Livingstone, F. Lips, P.G. Martinez and R.K. Pipe, Mar. Biol., 112, 265 (1992).

40. J.F. Zhang, X.R. Wang, H.Y. Guo, J.C. Wu and Y.Q. Xue, Ecotoxicol. Environ. Saf., 58, 110 (2004).

41. M. Ishizuka, T. Sakiyama, H. Iwata, M. Fukushima, A. Kazusaka and S. Fujita, Environ. Toxicol. Chem., 17, 1490 (1998).

42. F.H. Sun, Q.X. Zhou, M.E. Wang and J. An, J. Ecotoxicol. Environ. Safety, 72, 1887 (2009)

43. M. Solé, C. Porte, X. Biosca, C.L. Mitchelmore, J.K. Chipman, D.R. Livingstone and J. Albaigés, Comp. Biochem. Physiol. C Pharmacol. Toxicol. Endocrinol., 113, 257 (1996).

44. T. Milinkovitch, A. Ndiaye, W. Sanchez, S. Le Floch and H. ThomasGuyon, Aquat. Toxicol., 101, 155 (2011).

45. W.K. Kim, S.K. Lee and J. Jung, J. Hazard. Mater., 180, 395 (2010).

46. A. Dagnino, J.I. Allen, M.N. Moore, K. Broeg, L. Canesi and A. Viarengo, Biomarkers, 12, 155 (2007).

47. G.H. Lu, Y. Ji, H.Z. Zhang, H. Wu, J. Qin and C. Wang, Chemosphere, 79, 588 (2010). 